\title{
Causas de morte e razões para eutanásia em gatos na Região Central do Rio Grande do Sul (1964-2013) ${ }^{1}$
}

\author{
Monique Togni ${ }^{2 *}$, Andressa Curtis ${ }^{3}$, Diego P. Vargas ${ }^{4}$, Glaucia D. Kommers ${ }^{5}$, \\ Luiz Francisco Irigoyen ${ }^{5}$ Rafael A. Fighera ${ }^{5}$
}

\begin{abstract}
Togni M., Curtis A., Vargas D.P., Kommers G.D., Irigoyen L.F. \& Fighera R.A. 2018. [Causes of death and reason for euthanasia in cats in the central region of Rio Grande do Sul, Brazil (1964-2013)]. Causas de morte e razão para eutanásia em gatos na Região Central do Rio Grande do Sul (1964-2013). Pesquisa Veterinária Brasileira 38(4):741-750. Departamento de Patologia, Universidade Federal de Santa Maria, Santa Maria, RS 97105-900, Brazil. E-mail: anemiaveterinaria@yahoo.com.br

The objective of this study was to determine the main diseases that cause death or euthanasia in cats in the central region of Rio Grande do Sul, Brazil. The Veterinary Pathology Laboratory (LPV-UFSM) files were reviewed from 1964 to 2013 and a total of 1,247 cat necropsies protocols were found. In $878(70.40 \%)$ protocols the cause of death and/or reason for euthanasia has been established while in 369 (29.59\%) cases it was not possible to be determined and these were classified as inconclusive. The final diagnosis were evaluated and classified into different categories. The category which includes the largest number of causes of death or reason for euthanasia in cats are disorders due to physical agents (15.63\%), followed by infectious and parasitic diseases $(13.15 \%)$, tumors (10.50\%), other disorders $(8.34 \%)$, poisoning and toxinfections (5.29\%), degenerative diseases (4.81\%), iatrogenic disorders (3.76\%), metabolic and endocrinological diseases $(2.72 \%)$, immune-mediated diseases (2.08\%), nutritional diseases (1.60), convenience euthanasia (1.44\%) and congenital disorders $(1.04 \%)$. The most important diseases were also evaluated according to age and the results demonstrated that adult cats are most affected by lower urinary tract disease, trauma and iatrogenic disorders. Elderly cats are most affected by tumors and chronic renal failure. However, in young cats, feline infections peritonitis were found to be the most important cause of death or euthanasia.
\end{abstract}

INDEX TERMS: Euthanasia, cats, diseases of cats, retrospective study, pathology.

RESUMO.- Este trabalho tem por objetivo determinar a prevalência das doenças que causam a morte ou levam à eutanásia de gatos da região central do Rio Grande do Sul. Para isto, foram revisados os arquivos do Laboratório de Patologia

\footnotetext{
${ }^{1}$ Recebido em 10 de fevereiro de 2017.

Aceito em 19 de março de 2017.

Parte da tese de Doutorado do primeiro autor.

${ }^{2}$ Programa de Pós-Graduação em Medicina Veterinária, área de concentração em Patologia e Patologia Clínica Veterinária, Centro de Ciências Rurais (CCR), Universidade Federal de Santa Maria (UFSM), Camobi, Santa Maria, RS 97105-900, Brasil.

${ }^{3}$ North Shore Veterinary Hospital, 64 Atchison Street, 2065 Crows Nest, New South Wales, Australia.

${ }^{4}$ Departamento de Medicina Veterinária, Centro de Ciências da Saúde, Universidade do Oeste de Santa Catarina (Unoesc), Rua Oiapoc 211, São Miguel do Oeste, SC 89900-000, Brasil.

${ }^{5}$ Departamento de Patologia, Centro de Ciências da Saúde, Universidade Federal de Santa Maria (UFSM), Av. Roraima 1000, Santa Maria, RS 97105900. *Autor para correspondência: anemiaveterinaria@yahoo.com.br
}

Veterinária (LPV) da Universidade Federal de Santa Maria (UFSM) entre 1964 a 2013, e foram encontrados um total de 1.247 protocolos de necropsias de gatos. Em 878 protocolos $(70,4 \%)$ a causa da morte e/ou razão para eutanásia foi estabelecida e em 369 casos $(29,6 \%)$ não foi possível estabelecer uma causa definitiva. Os diagnósticos encontrados foram avaliados e distribuídos em diferentes categorias. Os grupos responsáveis pelo maior número de causas de morte ou razão para eutanásia em gatos foram os distúrbios causados por agentes físicos $(15,6 \%)$, seguidos das doenças infecciosas e parasitárias $(13,2 \%)$ e dos tumores $(10,50 \%)$. Intoxicações e toxi-infecções $(5,3 \%)$, doenças degenerativas $(4,8 \%)$, distúrbios iatrogênicos $(3,8 \%)$, doenças metabólicas e endocrinológicas $(2,7 \%)$ foram categorias comuns. Doenças imunomediadas $(2,1 \%)$, doenças nutricionais $(1,6 \%)$, eutanásia por conveniência $(1,4 \%)$ e distúrbios congênitos $(1 \%)$ foram categorias incomuns. Outros distúrbios perfizeram $8,34 \%$ dos casos, As doenças mais importantes também foram avaliadas 
com relação à idade e os resultados obtidos demonstram que os adultos são mais acometidos pelo distúrbio do trato urinário inferior dos felinos, por traumas e por distúrbios iatrogênicos. Os gatos idosos são mais afetados por tumores e por doenças degenerativas, como a insuficiência renal crônica. Nos filhotes a principal doença que causa a morte ou eutanásia é a peritonite infecciosa felina

TERMOS DE INDEXAÇÃO: Eutanásia, doenças de felinos, estudo retrospectivo, patologia.

\section{INTRODUÇÃO}

Atualmente, os gatos contribuem com uma importante parcela dos atendimentos clínicos veterinários em nosso país e, consequentemente, o número de necropsias nessa espécie vem aumentando. Logo, uma revisão acerca das principais causas de morte e razões para eutanásia se faz necessária, tanto do ponto de vista do patologista como do clínico de pequenos animais (Landes et al. 1984), pois as informações fornecidas por este modelo de estudo são de grande importância para monitoramento, planejamento e ações que auxiliem o tratamento e a prevenção das doenças que mais frequentemente acarretam na morte de uma determinada espécie animal (Bonnett et al. 2005).

Estudos sobre causas de morte em pequenos animais ainda são escassos no Brasil (Trapp et al. 2010) e os que estão disponíveis contemplam apenas cães (Bentubo et al. 2007, Fighera et al. 2008). Trabalhos sobre doenças em gatos no Rio Grande do Sul apenas foram realizados com base em doenças ou síndromes especificas (Wouters et al. 1998, Souza et al. 2002, Oliveira et al. 2003, Ilha et al. 2004, Headley 2005, Correa et al. 2009, Andrade et al. 2012, Togni et al. 2013). Como os estudos foram realizados em diferentes épocas, direcionados apenas para uma doença ou síndrome específicas e em uma população variante, ainda encontram-se dificuldades em estabelecer a real prevalência das principais doenças que acarretam na morte ou na eutanásia de gatos na Região Central do Rio Grande do Sul.

Nos últimos 10 anos, o Laboratório de Patologia Veterinária (LPV) da Universidade Federal de Santa Maria (UFSM) tem estabelecido a prevalência das diferentes doenças que afetam cães (Fighera et al. 2008), equinos (Pierezan et al. 2009), ovinos (Rissi et al. 2010), bovinos (Lucena et al. 2010), chinchilas (Lucena et al. 2012), caprinos (Rosa et al. 2013) e suínos (Brum et al. 2013). Esse artigo tem por objetivo principal mostrar, aos veterinários que trabalham com medicina felina, a prevalência das doenças responsáveis pela morte ou que são razão para eutanásia dessa espécie na Região Central do Rio Grande do Sul e, com isso, finalizar essa série de estudos conduzidos no LPV-UFSM.

\section{MATERIAL E MÉTODOS}

Os protocolos de necropsia compreendidos entre janeiro de 1964 e dezembro de 2013 do arquivo do Laboratório de Patologia Veterinária (LPV) da Universidade Federal de Santa Maria (UFSM) foram revisados. A escolha dos dados a serem coletados dos protocolos (categoria etária, gênero e raça) e a escolha de um único diagnóstico definitivo como causa de morte ou razão para eutanásia, mesmo alguns animais apresentando mais de uma lesão, foi baseada em diversos estudos semelhantes já realizados em cães (Moore et al.
2001, Bonnett et al. 2005, Fighera et al. 2008) e gatos (Landes et al. 1984, Olsen \& Allen 2001, Trapp et al. 2010).

Em relação à categoria etária há muitas divergências no que se refere à espécie felina. Neste estudo, os gatos foram classificados de acordo com a faixa etária em: filhotes (menos de um ano de idade), adultos (de um a nove anos de idade) e idoso (com 10 anos ou mais de idade) segundo uma interação de alguns autores (Mooney 1995, Hoskins 2008). Protocolos incompletos, com ausência de dados relevantes ao estudo, foram computados como não informados (n.i.).

As causas de morte ou razões para eutanásia estabelecidas através da avaliação dos protocolos foram subdivididas nas seguintes categorias: distúrbios causados por agentes físicos, doenças infecciosas e parasitárias, tumores, intoxicações e toxi-infecções, doenças degenerativas, distúrbios iatrogênicos, distúrbios congênitos, doenças imunomediadas, doenças metabólicas e endocrinológicas e doenças nutricionais. Os casos em que a eutanásia ocorreu sem um motivo médico justificável, como quando a doença apresentada pelo paciente era passível de tratamento e não levaria o animal à morte, foram incluídos em "eutanásia por conveniência". Casos em que não foi possível estabelecer a causa da morte foram classificados como "inconclusivos" e quando as doenças não puderam ser incluídas em nenhuma das categorias anteriores, foram agrupadas como "outros distúrbios".

A prevalência das categorias por faixa etária foi contemplada no Quadro 1, assim como as principais doenças diagnosticadas por faixa etária contempladas no Quadro 2. Os diagnósticos atribuídos a cada categoria foram agrupados nos Quadros 3 a 9.

As variáveis categorias das doenças diagnosticadas e faixa etária foram determinadas por meio de tabelas de frequência. Com o objetivo de verificar a associação estas variáveis, estabeleceu-se o valor de p por meio do teste exato de Fisher ao nível de 5\% de significância. As análises estatísticas dessa metodologia foram executadas através do procedimento PROC FREQ no aplicativo SAS ${ }^{\circledR}$ System for Windows ${ }^{\mathrm{TM}}$ versão 9.0 (SAS Institute Inc., Cary, NC, USA).

\section{RESULTADOS}

Entre 1964 e 2013 foram encontrados 1.247 protocolos de necropsias de gatos. Destes, em 878 casos (70,4\%), a causa da morte ou a razão para eutanásia foi estabelecida e as doenças apresentadas por esses pacientes foram classificadas de acordo com as categorias previamente determinadas. Em 369 (29,6\%) casos não foi possível estabelecer uma doença definitiva; estes casos foram classificados como inconclusivos.

Do total de casos em que o sexo foi informado nos protocolos $(\mathrm{n}=1.203)$, as fêmeas totalizam $575(47,8 \%)$ e os machos $628(52,2 \%)$. Do total de casos em que a raça foi informada nos protocolos $(n=1.141)$, gatos sem raça definida foram os mais frequentes, perfazendo 869 casos (76,2\%). Apenas 272 gatos $(23,8 \%)$ eram de raça pura. Entre estes, a raça Siamês foi a mais prevalente $(48,5 \%)$, seguido das raças Persa $(39,3 \%)$, Himalaia (17\%), Angorá (11\%), Ragdoll $(0,7 \%)$, Oriental, Exótico e Bengal com 0,4\% cada. Do total de casos em que a idade foi informada nos protocolos $(n=1.109)$, gatos adultos foram os mais necropsiados, totalizando 622 casos $(56,1 \%)$, seguido de 335 filhotes $(30,2 \%)$ e de 152 idosos $(13,7 \%)$.

Quanto às categorias, as doenças diagnosticadas como causa de morte ou razão para eutanásia seguiram a seguinte ordem decrescente de prevalência: distúrbios causados por agentes físicos, doenças infecciosas e parasitárias, tumores, intoxicações e toxi-infecções, doenças degenerativas, distúrbios iatrogênicos, doenças metabólicas e endocrinológicas, 
Quadro 1. Prevalência geral e por faixa etária das categorias de doenças diagnosticadas em gatos necropsiados no LPV-UFSM de 1964-2013

\begin{tabular}{|c|c|c|c|c|}
\hline Doença & $\mathrm{N}(\%)$ & Filhote(\%) & Adulto(\%) & $\operatorname{Idoso}(\%)$ \\
\hline Distúrbios causados por agentes físicos & $195(15,6)$ & $68(34,9)$ & $91(46,7)$ & $11(5,6)$ \\
\hline Doenças infecciosas e parasitárias & $164(13,2)$ & $63(38,4)$ & $74(45,1)$ & $7(4,3)$ \\
\hline Tumores & $131(10,5)$ & $6(4,6)$ & $45(34,4)$ & $70(53,4)$ \\
\hline Doenças degenerativas & $60(4,8)$ & $4(6,7)$ & $32(53,3)$ & $21(35)$ \\
\hline Distúrbios iatrogênicos & $47(3,8)$ & $18(38,3)$ & $20(42,6)$ & $3(6,4)$ \\
\hline Doenças nutricionais & $20(1,6)$ & $14(70)$ & $3(15)$ & $1(5)$ \\
\hline Eutanásia por conveniência & $18(1,4)$ & $1(5,5)$ & $13(72,2)$ & $3(16,7)$ \\
\hline Distúrbios congênitos & $13(1,0)$ & $10(76,9)$ & $3(23,1)$ & - \\
\hline Outros distúrbios & $104(8,3)$ & $10(9,6)$ & $79(73,1)$ & $5(4,8)$ \\
\hline Inconclusivos & $369(29,6)$ & $126(34,1)$ & $181(49,1)$ & $17(4,6)$ \\
\hline
\end{tabular}

Quadro 2. Causas de morte e razão para eutanásia em gatos $(\mathrm{n}=1.247)$. Principais causas de morte ou razões para eutanásia diagnosticadas em gatos necropsiados no LPV-UFSM de 1964-2013

\begin{tabular}{|c|c|c|c|c|c|c|c|}
\hline \multirow{2}{*}{ Doenças/categoria } & \multirow{2}{*}{$\mathrm{N}$ total/NIE } & \multicolumn{2}{|c|}{ Filhote } & \multicolumn{2}{|c|}{ Adulto } & \multicolumn{2}{|c|}{ Idoso } \\
\hline & & $\mathrm{N}$ & $\%$ NIE & $\mathrm{N}$ & $\% \mathrm{NIE}$ & $\mathrm{N}$ & $\%$ NIE \\
\hline Trauma & $176 / 152$ & 59 & 38,8 & 84 & 55,2 & 9 & 5,9 \\
\hline Tumores & $132 / 120$ & 6 & 5 & 45 & 37,5 & 69 & 57,5 \\
\hline DTUIF & $64 / 61$ & 4 & 6,5 & 54 & 88,5 & 3 & 4,9 \\
\hline PIF & $51 / 50$ & 27 & 54 & 23 & 46 & - & - \\
\hline Distúrbios iatrogênicos & $47 / 42$ & 18 & 42,8 & 21 & 50 & 3 & 7,1 \\
\hline Lipidose hepática idiopática felina & $26 / 26$ & 4 & 15,3 & 18 & 69,2 & 4 & 15,3 \\
\hline Intoxicação aguda por carbamato & $25 / 18$ & 1 & 5,5 & 16 & 88,8 & 1 & 5,5 \\
\hline Piotórax idiopático felino & $22 / 21$ & 4 & 19 & 16 & 76,1 & 1 & 4,7 \\
\hline Pneumonia bacteriana & $19 / 16$ & 5 & 31,2 & 11 & 68,7 & - & - \\
\hline Eutanásia por conveniência & $18 / 17$ & 1 & 5,8 & 13 & 76,4 & 3 & 17,6 \\
\hline Distúrbios congênitos & $13 / 13$ & 10 & 76,9 & 3 & 23 & - & - \\
\hline Sepse & $13 / 9$ & 3 & 33,3 & 6 & 66,6 & - & - \\
\hline Rinotraqueíte infecciosa felina & $10 / 10$ & 8 & 80 & 2 & 20 & - & - \\
\hline Inanição & $9 / 9$ & 8 & 88,8 & 1 & 11,1 & - & - \\
\hline Osteodistrofia fibrosa & $8 / 8$ & 6 & 75 & 2 & 208 & - & - \\
\hline Verminose intestinal & $7 / 4$ & 4 & 100 & - & - & - & - \\
\hline
\end{tabular}

$\overline{\mathrm{NIE}}$ = número com idade estabelecida, DTUIF = distúrbio do trato urinário inferior dos felinos, PIF = peritonite infecciosa felina, $\mathrm{SCCH}=$ síndrome colangite-colângio-hepatite.

Quadro 3. Causas de morte e razões para eutanásia de gatos $(\mathrm{n}=1.247)$. Distúrbios causados por agentes físicos diagnosticados em gatos necropsiados no LPV-UFSM de 1964-2013

\begin{tabular}{lccc}
\hline \multicolumn{1}{c}{ Localização/classificação } & $\mathrm{N}$ & \% categoria & \% total \\
\hline Traumas & $\mathbf{1 7 6}$ & $\mathbf{9 0 , 5}$ & $\mathbf{1 4 , 3 1}$ \\
Trauma com causa estabelecida & 91 & 46,7 & 7,3 \\
Atropelamento por veiculo automotivo & 32 & 16,4 & 2,6 \\
Interação animal & 30 & 15,4 & 2,4
\end{tabular}


Quadro 3. Continuação...

\begin{tabular}{|c|c|c|c|}
\hline Localização/classificação & $\mathrm{N}$ & \% categoria & $\%$ total \\
\hline Por cães & 26 & 13,3 & 2,1 \\
\hline Entre gatos & 4 & 2,1 & 0,3 \\
\hline Agressão por humanos & 18 & 9,2 & 1,4 \\
\hline Trauma contuso & 9 & 4,6 & 0,7 \\
\hline Trauma perfurocontundente & 9 & 4,6 & 0,7 \\
\hline Quedas & 11 & 5,6 & 0,9 \\
\hline Trauma sem causa estabelecida & 85 & 43,6 & 6,8 \\
\hline Obstruções e perfurações do sistema digestório & 15 & 7,7 & 1,2 \\
\hline Obstrução & 10 & 5,1 & 0,8 \\
\hline Corpo estranho (intestinal) & 4 & 2,0 & 0,3 \\
\hline Intussuscepção (intestinal) & 1 & 0,5 & 0,1 \\
\hline Torção (intestinal) & 1 & 0,5 & 0,1 \\
\hline Fecaloma & 4 & 2,0 & 0,3 \\
\hline Perfuração & 5 & 2,6 & 0,4 \\
\hline Esofágica & 2 & 1,0 & 0,2 \\
\hline Intestinal & 2 & 1,0 & 0,2 \\
\hline Gástrica & 1 & 0,5 & 0,1 \\
\hline Pneumonia por aspiração & 4 & 2,0 & 0,3 \\
\hline TOTAL & 195 & & \\
\hline
\end{tabular}

Quadro 4. Causas de morte e razões para eutanásia de gatos (n=1.247). Doenças infecciosas e parasitárias diagnosticadas em gatos necropsiados no LPV-UFSM de 1964-2013

\begin{tabular}{|c|c|c|c|}
\hline Doença & $\mathrm{N}$ & $\%$ categoria & $\%$ total \\
\hline Peritonite infecciosa felina & 51 & 31,1 & 4,1 \\
\hline Pneumonia bacteriana & 19 & 11,6 & 1,5 \\
\hline Sepse & 13 & 7,9 & 1,0 \\
\hline Rinotraqueíte infecciosa felina & 10 & 6,1 & 0,8 \\
\hline Panleucopenia felina & 7 & 4,3 & 0,6 \\
\hline Verminose intestinal & 7 & 4,3 & 0,6 \\
\hline Sinusite e rinite bacterianas & 6 & 3,7 & 0,5 \\
\hline Criptococose & 5 & 3,0 & 0,4 \\
\hline Elurostrongilose & 5 & 3,0 & 0,4 \\
\hline Calicivirose & 4 & 2,4 & 0,3 \\
\hline Paraplegia crural parasitária & 4 & 2,4 & 0,3 \\
\hline Raiva & 4 & 2,4 & 0,3 \\
\hline Esporotricose & 3 & 1,8 & 0,2 \\
\hline Tuberculose & 3 & 1,8 & 0,2 \\
\hline Toxoplasmose & 2 & 1,2 & 0,2 \\
\hline Capilariose hepática & 2 & 1,2 & 0,2 \\
\hline Síndrome colangite-colângio-hepatite aguda & 2 & 1,2 & 0,2 \\
\hline Onfaloflebite & 2 & 1,2 & 0,2 \\
\hline Endocardite valvar bacteriana & 2 & 1,2 & 0,2 \\
\hline Abscesso encefálico & 2 & 1,2 & 0,2 \\
\hline Micobacteriose sistêmica & 1 & 0,6 & 0,1 \\
\hline Pitiose gastrintestinal & 1 & 0,6 & 0,1 \\
\hline Panoftalmite bacteriana & 1 & 0,6 & 0,1 \\
\hline Micoplasmose hemotrópica & 1 & 0,6 & 0,1 \\
\hline Candidíase sistêmica & 1 & 0,6 & 0,1 \\
\hline Pulicose & 1 & 0,6 & 0,1 \\
\hline Zigomicose intestinal & 1 & 0,6 & 0,1 \\
\hline Osteomielite (maxilar) & 1 & 0,6 & 0,1 \\
\hline Yersiniose & 1 & 0,6 & 0,1 \\
\hline Pancreatite bacteriana & 1 & 0,6 & 0,1 \\
\hline Endometrite bacteriana & 1 & 0,6 & 0,1 \\
\hline TOTAL & 164 & & \\
\hline
\end{tabular}


Quadro 5. Causas de morte e razões para eutanásia de gatos (n=1.247). Classificação e localização dos neoplasmas diagnosticados em gatos necropsiados no LPV-UFSM de 1964-2013

\begin{tabular}{|c|c|c|c|}
\hline Localização/classificação & $\mathrm{N}$ & $\%$ categoria & $\%$ total \\
\hline Sistema hematopoiético & 37 & 28,24 & 2,96 \\
\hline Multicêntricos & 13 & 9,92 & 1,04 \\
\hline Linfoma & 9 & 6,87 & 0,72 \\
\hline Sarcoma histiocítico disseminado & 4 & 3,05 & 0,32 \\
\hline Medula óssea & 11 & 8,39 & 0,88 \\
\hline Leucemia & 11 & 8,39 & 0,88 \\
\hline Timo & 6 & 4,58 & 0,48 \\
\hline Linfoma tímico & 6 & 4,58 & 0,48 \\
\hline Baço & 4 & 3,05 & 0,32 \\
\hline Hemangiossarcoma & 3 & 2,29 & 0,24 \\
\hline Hemangioma & 1 & 0,76 & 0,08 \\
\hline Linfonodos & 3 & 2,29 & 0,24 \\
\hline Linfoma alimentar & 3 & 2,29 & 0,24 \\
\hline Sistema Tegumentar & 26 & 19,84 & 2,08 \\
\hline Pele & 26 & 19,84 & 2,08 \\
\hline Carcinoma de células escamosas & 22 & 16,79 & 1,76 \\
\hline Mastocitoma & 2 & 1,52 & 0,16 \\
\hline Melanoma & 1 & 0,76 & 0,08 \\
\hline Fibrossarcoma & 1 & 0,76 & 0,08 \\
\hline Glândula mamária & 18 & 13,74 & 1,44 \\
\hline Carcinoma & 18 & 13,74 & 1,44 \\
\hline Fígado e Vesícula biliar & 12 & 9,16 & 0,96 \\
\hline Fígado & 11 & 8,39 & 0,88 \\
\hline Colangiocarcinoma & 9 & 6,87 & 0,72 \\
\hline Carcinoma hepatocelular & 1 & 0,76 & 0,08 \\
\hline Linfoma extra-nodal & 1 & 0,76 & 0,08 \\
\hline Vesícula biliar & 1 & 0,76 & 0,08 \\
\hline Carcinoma & 1 & 0,76 & 0,08 \\
\hline Sistema respiratório & 10 & 7,63 & 0,80 \\
\hline Pulmão & 7 & 5,34 & 0,56 \\
\hline Carcinoma & 7 & 5,34 & 0,56 \\
\hline Seios paranasais & 1 & 0,76 & 0,08 \\
\hline Adenocarcinoma & 1 & 0,76 & 0,08 \\
\hline Laringe & 1 & 0,76 & 0,08 \\
\hline Carcinoma de células escamosas & 1 & 0,76 & 0,08 \\
\hline Tabique mediastínico & 1 & 0,76 & 0,08 \\
\hline Hemangiossarcoma & 1 & 0,76 & 0,08 \\
\hline Trato alimentar & 9 & 6,87 & 0,80 \\
\hline Intestino & 2 & 1,52 & 0,24 \\
\hline Tumor de mastócitos & 1 & 0,76 & 0,08 \\
\hline Adenocarcinoma de ampola hepatopancreática & 1 & 0,76 & 0,08 \\
\hline Língua & 2 & 1,52 & 0,16 \\
\hline Carcinoma de células escamosas & 2 & 1,52 & 0,16 \\
\hline Gengiva & 2 & 1,52 & 0,16 \\
\hline Carcinoma de células escamosas & 2 & 1,52 & 0,16 \\
\hline Estômago & 2 & 1,52 & 0,16 \\
\hline Leiomiossarcoma & 1 & 0,76 & 0,08 \\
\hline Adenocarcinoma & 1 & 0,76 & 0,08 \\
\hline Palato duro & 1 & 0,76 & 0,08 \\
\hline Mixossarcoma & 1 & 0,76 & 0,08 \\
\hline Pâncreas exócrino & 5 & 3,81 & 0,40 \\
\hline Carcinoma & 5 & 3,81 & 0,40 \\
\hline Sistema nervoso & 4 & 3,05 & 0,32 \\
\hline Encéfalo & 4 & 3,05 & 0,32 \\
\hline
\end{tabular}


Quadro 5. Continuação...

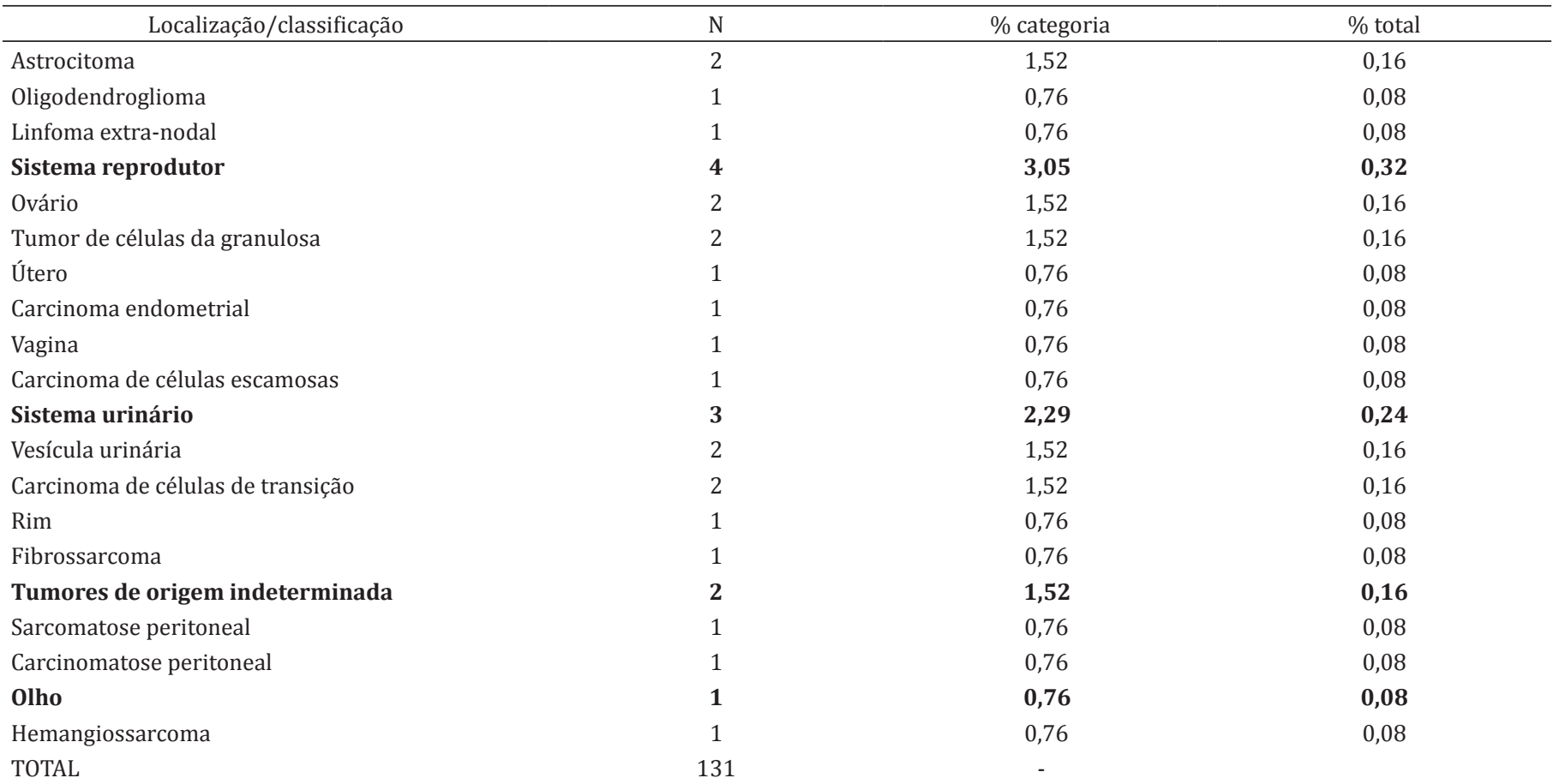

Quadro 6. Causas de morte e razões para eutanásia de gatos $(\mathrm{n}=1.247)$. Outros distúrbios diagnosticados em gatos necropsiados no LPV-UFSM de 1964-2013

\begin{tabular}{|c|c|c|c|}
\hline Doença & $\mathrm{N}$ & $\%$ categoria & $\%$ total \\
\hline Distúrbio do trato urinário inferior dos felinos & 64 & 61,13 & 5,13 \\
\hline Piotórax idiopático felino & 22 & 21,15 & 1,76 \\
\hline Choque neurogênico por estresse (banho/contenção) & 6 & 5,76 & 4,72 \\
\hline Peritonite (sem causa estabelecida) & 5 & 4,80 & 0,40 \\
\hline Torção uterina & 2 & 1,92 & 0,16 \\
\hline Meningoencefalomielite não supurativa & 2 & 1,92 & 0,16 \\
\hline Endometrite & 1 & 0,96 & 0,08 \\
\hline Meningite eosinofílica & 1 & 0,96 & 0,08 \\
\hline Fibroplasia esclerosante gastrointestinal eosinofílica felina & 1 & 0,96 & 0,08 \\
\hline TOTAL & 104 & & \\
\hline
\end{tabular}

Quadro 7. Causas de morte e razões para eutanásia de gatos $(\mathrm{n}=1.247)$. Intoxicações e toxiinfecções diagnosticadas em gatos necropsiados no LPV-UFSM de 1964-2013

\begin{tabular}{|c|c|c|c|}
\hline Doença & $\mathrm{N}$ & $\%$ categoria & $\%$ total \\
\hline Nefrose tóxica aguda & 31 & 46,69 & 2,48 \\
\hline Intoxicação aguda por carbamato & 25 & 37,87 & 2,00 \\
\hline Intoxicação por estricnina & 4 & 6,06 & 0,32 \\
\hline Crise hemolítica por agentes oxidantes* & 2 & 3,03 & 0,16 \\
\hline Intoxicação por triclorfon & 1 & 1,51 & 0,08 \\
\hline Intoxicação por piretroide & 1 & 1,51 & 0,08 \\
\hline Intoxicação por ivermectina & 1 & 1,51 & 0,08 \\
\hline Hepatopatia tóxica aguda & 1 & 1,51 & 0,08 \\
\hline TOTAL & 66 & & \\
\hline
\end{tabular}

\footnotetext{
*Agentes oxidantes: paracetamol e metionina.
} 
Quadro 8. Causas de morte e razões para eutanásia de gatos $(\mathrm{n}=1.247)$. Doenças degenerativas diagnosticados em gatos necropsiados no LPV-UFSM de 1964-2013

\begin{tabular}{lccc}
\hline \multicolumn{1}{c}{ Doença } & $\mathrm{N}$ & \% categoria & \% total \\
\hline Doença renal crônica & 29 & 48,33 & 2,32 \\
Miocardiopatia hipertrófica idiopática & 14 & 23,33 & 1,12 \\
Cirrose hepática idiopática & 7 & 11,66 & 0,56 \\
Doença renal policística & 4 & 6,66 & 0,32 \\
Miocardiopatia dilatada idiopática & 4 & 6,66 & 0,32 \\
Pancreatite crônica & 1 & 1,66 & 0,08 \\
Doença do disco intervertebral & 1 & 1,66 & 0,08 \\
TOTAL & 60 & &
\end{tabular}

Quadro 9. Causas de morte e razões para eutanásia de gatos (n=1.247). Outras categorias de doenças e distúrbios diagnosticados em gatos necropsiados no LPV-UFSM de 1964-2013

\begin{tabular}{|c|c|c|c|}
\hline Doenças & $\mathrm{N}$ & \% categoria & $\%$ total \\
\hline Distúrbios iatrogênicos & 47 & - & 3,7 \\
\hline Gastropatia induzida por fármaco & 20 & 42,55 & 1,60 \\
\hline Insuficiência renal aguda & 1 & 2,12 & 0,08 \\
\hline Intervenção cirúrgica & 17 & 36,17 & 1,36 \\
\hline Intervenção anestésica & 7 & 14,89 & 0,56 \\
\hline Lipidose hepática idiopática felina & 26 & 76,47 & 2,80 \\
\hline Complexo hiperplasia endometrial cística/piometra & 5 & 14,70 & 0,40 \\
\hline Diabete melito & 2 & 5,88 & 0,16 \\
\hline Pancreatite aguda & 1 & 2,94 & 0,08 \\
\hline Doenças imunomediadas & 26 & - & 2,08 \\
\hline Síndrome colangite-colângio-hepatite subaguda/crônica & 15 & 57,69 & 1,20 \\
\hline Asma & 1 & 3,84 & 0,08 \\
\hline Trombocitopenia autoimune & 1 & 3,84 & 0,08 \\
\hline Anafilaxia & 1 & 3,84 & 0,08 \\
\hline Doenças nutricionais & 20 & - & 1,60 \\
\hline Inanição & 9 & 45 & 0,72 \\
\hline Osteodistrofia fibrosa & 8 & 40 & 0,64 \\
\hline Raquitismo & 2 & 10 & 0,16 \\
\hline Deficiência de tiamina & 1 & 5 & 0,08 \\
\hline Eutanásia por conveniência & 18 & - & 1,44 \\
\hline Tumores benignos & 6 & 33,33 & 0,48 \\
\hline Comportamental & 5 & 27,77 & 0,40 \\
\hline Defeito do septo atrial & 1 & 7,69 & 0,08 \\
\hline Persistência do arco aórtico direito & 1 & 7,69 & 0,08 \\
\hline Fenda palatina & 1 & 7,69 & 0,08 \\
\hline Megacólon & 1 & 7,69 & 0,08 \\
\hline Hérnia umbilical & 1 & 7,69 & 0,08 \\
\hline
\end{tabular}

\footnotetext{
*Em um desses casos havia agenesia uretral e prepucial.
} 
doenças imunomediadas, doenças nutricionais, eutanásia por conveniência e distúrbios congênitos. A prevalência dessas categorias pode ser contemplada no Quadro 1.

Todos os diagnósticos atribuídos como causa de morte ou razão para eutanásia incluídos em cada categoria citada anteriormente, podem ser visualizados nos Quadros 3-9. As principais doenças diagnosticadas em gatos no LPV foram avaliadas de acordo com a idade e estão incluídas no Quadro 2.

De acordo com a categoria os distúrbios causados por agentes, doenças infecciosas e parasitárias, intoxicações e toxi-infecções, doenças degenerativas, distúrbios iatrogênicos, doenças metabólicas e endocrinológicas, doenças imunomediadas e eutanásia por conveniência ocorrem mais em adultos $(\mathrm{p}<0,0001)$. Tumores acometem mais idosos $(\mathrm{p}<0,0001)$ e doenças nutricionais e distúrbios congênitos estão entre as categorias que contemplam uma maior número de diagnósticos post mortem em filhotes $(\mathrm{p}<0,0001)$.

Tratando-se das doenças diagnosticadas em gatos, conforme o Quadro 2, a morte ou eutanásia de filhotes ocorre principalmente devido a trauma e peritonite infecciosa felina (PIF) $(\mathrm{p}<0,0001)$, em adultos devido a trauma e distúrbio do trato urinário inferior dos felinos (DTUIF) $(\mathrm{p}<0,0001)$, e em idosos por tumores e doença renal crônica $(\mathrm{p}<0,0001)$.

\section{DISCUSSÃO}

Dos 1.247 gatos necropsiados entre os anos de 1964-2013, $15,6 \%$ das mortes ocorreram em decorrência de distúrbios causados por agentes físicos, sendo esta a categoria mais frequente de morte em gatos em nossa região. 0 trauma foi responsável por mais de $90 \%$ das mortes ou eutanásias nesta categoria, à semelhança do que foi descrito em estudos semelhantes no Canadá (Olsen \& Allen 2001) e no Brasil (Trapp et al. 2010). Possivelmente os resultados encontrados neste estudo decorram dos hábitos dos gatos, que em nossa região, geralmente, possuem livre acesso a rua, o que associado ao alto fluxo de veículos circulantes possibilita o atropelamento por veículo automotivo, a maior causa de morte por trauma nesta espécie.

A segunda categoria com maior número de diagnósticos neste estudo foram as doenças infecciosas e parasitárias. A importância desta categoria também foi observada na Alemanha (Landes et al. 1984) e no Brasil no estado do Piauí (Batista et al. 2016), sendo para estes a categoria de doenças infecciosas e parasitárias a principal causa de morte em gatos. A peritonite infecciosa felina (PIF) foi a doença infecciosa mais prevalente em nossa região e a quarta principal doença no geral como causa de morte ou razão eutanásia, principalmente em filhotes. Esses resultados assemelham-se aos descritos para a Alemanha (Landes et al. 1984) e para o Reino Unido (Cave et al. 2002). Provavelmente as altas prevalências de causas de morte ou razões para eutanásia por doenças infecciosas e parasitárias em nossa região são oriundas da falta de conhecimento e conscientização dos proprietários com relação ao plano de vacinação e everminação na espécie felina, ainda pouco difundidos em algumas regiões do país. Além de, como citado anteriormente, os gatos da Região Central do Rio Grande do Sul geralmente possuem livre acesso à rua e a outros gatos, facilitando uma maior probabilidade de transmissão de doenças infectocontagiosas como a PIF.

Tumores totalizaram $10,5 \%$ das necropsias de gatos realizadas no LPV resultado semelhante encontrado por
Batista et al. (2016). A maior prevalência ocorre em idosos $(53,43 \%)$, semelhante aos resultados encontrados em outros estudos (Landes et al. 1984, Andrade et al. 2012). Dados como estes corroboram a afirmação de que com o aumento da longevidade cresce a incidência de câncer em cães e gatos (Moore et al. 2001, Bonnett et al. 2005, Rodaski \& Piekarz 2009). Apesar de sabermos, através de estudos anteriores (Togni et al. 2013), que os tumores cutâneos são os mais diagnosticados em gatos de nossa região, os tumores hematopoiéticos são os que mais causam a morte ou levam à eutanásia desta espécie na região. Assim como no estudo de Landes et al. (1984), o linfoma foi o tumor mais comum. A alta prevalência de tumores hematopoiéticos pode estar associada à alta infecção dos gatos pelo vírus da leucemia felina (FeLV), visto que alguns desses tumores podem estar até $70 \%$ associados à infecção por estes vírus (Fighera \& Graça 2011). Até o fim da década de 90 não haviam registros nos protocolos entre a relação dos diagnósticos post mortem estabelecidos com os vírus da leucemia felina (FeLV) e o vírus da imunodeficiência felina (FIV). E quando mencionada, apenas nos últimos anos deste estudo, não obtinham comprovação por outros métodos diagnósticos, como testes sorológicos. Portanto, estudos atualizados da prevalência destes vírus na região estão sendo realizados para que sustentem a hipótese de uma possível relação destes com alguns dos resultados obtidos neste manuscrito.

Distúrbio do trato urinário inferior dos felinos (DTUIF) foi a condição mais diagnosticada na categoria "outros distúrbios", responsável por 8,3\% das mortes ou razão para eutanásia em gatos, e a terceira condição mais importante no geral (5,13\%). O DTUIF acometeu principalmente gatos adultos, assim como nos resultados apresentados por Landes et al. (1984) e Batista et al. (2016). A taxa desta condição varia conforme a região avaliada, sendo a segunda causa de morte em gatos no interior do estado do Paraná (Trapp et al. 2010) e Piauí (Batista et al. 2016), com menor frequência, mas não menos importante na Alemanha com 2,98\% (Landes et al. 1984 ) e pouco frequente no Canadá $(1,26 \%)$ (Olsen \& Allen 2001). Essa diferença deve-se possivelmente a variação de manejo destes gatos em cada região estudada, pois se acredita que alguns fatores como a variação na alimentação (seca ou úmida), quantidade de ingestão de água diária, estado nutricional, atividade física e a castração podem predispor o desenvolvimento do DTUIF (Gaskell 2006). Ainda podemos associar a alta frequência de morte em gatos por DTUIF com o livre acesso à rua, impossibilitando assim a observação do tutor quanto alterações comportamentais e urinárias.

As intoxicações e toxi-infecções foram responsáveis por $5,3 \%$ das causas de morte ou razão para eutanásia. Na Alemanha, essa prevalência é de 3,7\% (Landes et al. 1984), e no estado do Paraná é de 6,66\% (Trapp et al. 2010). Nefrose tóxica aguda foi responsável por com 46,7\% das intoxicações. Embora existam outras possíveis etiologias para essa lesão, como nefrotoxicidade causada pelo lírio (gêneros Lilium e Hemerocallis) (Hall 2006), a ausência de outros achados epidemiológicos, e clinicopatológicos associados nos faz acreditar que os agentes terapêuticos como sulfonamidas, tetraciclinas e anti-inflamatórios não esteroidais (AINES), como descritos por Barber (2006), sejam os principais responsáveis por essa condição. Porém, devido à ausência de informações nos protocolos referentes à administração 
desses medicamentos, a nefrose tóxica aguda não pode ser incluída por nós na categoria dos distúrbios iatrogênicos.

As doenças degenerativas totalizaram 4,8\% dos casos, sendo a doença renal crônica (DRC) a principal doença desta categoria e a sétima doença mais importante dentre todas as diagnosticadas. A DRC, juntamente com os tumores, está entre as principais condições responsáveis pela morte ou eutanásia de gatos idosos, bem como os dados apresentados na Alemanha (Landes et al. 1984). Em um estudo realizado em Portugal, apenas com causa de morte em gatos idosos, a doença renal crônica foi a síndrome mais diagnosticada (Manteigas 2013). Apesar de sua etiologia ser dificilmente determinada, sabese que gatos acima de 10 anos são acometidos com maior frequência (Barber 2006), demonstrando assim que a DRC é uma importante síndrome a ser incluída em diagnósticos diferenciais de gatos nessa faixa etária.

As causas de morte ou razões para eutanásia por distúrbios iatrogênicos totalizaram 3,8\% dos gatos necropsiados. Esses resultados estão muito acima dos apresentados por Landes et al. (1984), que demonstra que apenas 1,9\% das causas de morte ocorreram devido a intervenções cirúrgicas e anestésicas. Em outros estudos semelhantes essa categoria nem ao menos foi citada. A gastropatia induzida por fármacos utilizados como terapia clínica ou administradas como profilaxia pré ou pós-operatória foram a maior causa de morte em gatos nessa categoria. Sabe-se que fármacos anti-inflamatórios, principalmente os AINES, são frequentemente associados a úlceras gastrointestinais ou à gastrite hemorrágica (Willard 2009). Acreditamos que possa haver uma associação entre a medicação administrada e o estresse no qual o paciente é submetido, tanto pelo procedimento realizado como pela mudança ambiental a qual é submetido durante o procedimento clinico e/ou cirúrgico.

Doenças metabólicas e endocrinológicas contribuíram com 2,7\% dos diagnósticos, sendo a lipidose hepática idiopática felina a condição de maior frequência nesta categoria e a oitava doença como causa de morte ou razão para eutanásia em gatos (2,8\%). Os gatos mais afetados foram os adultos, à semelhança com o que é descrito na literatura (Stonehewer 2006). Casos de Lipidose hepática idiopática foram encontrados por Landes et al. (1984) como a maior causa de morte relacionada ao sistema hepatobiliar em gatos $(0,48 \%)$. Em outros estudos semelhantes, esta categoria não foi incluída. Nessa classificação foram descartadas doenças que possam resultar na síndrome de lipidose hepática, como diabetes melito, hipertireoidismo, neoplasias e pancreatite (Stonehewer 2006), ou seja, apenas casos realmente idiopáticos de lipidose hepática. As doenças imunomediadas perfizeram pouco mais que $2 \%$ dos casos. A síndrome colangite-colângiohepatite foi a mais diagnosticada nesta categoria, com $1,2 \%$, principalmente em gatos adultos. Resultado acima do encontrado em um estudo realizado nos Estados Unidos, onde apenas $0,07 \%$ do total de gatos necropsiados receberam este diagnóstico (Callahan Clark et al. 2011). Sua etiologia ainda obscura (Stonehewer 2006, Watson \& Bunch 2009) dificulta a formação de uma hipótese que possa explicar a causa do alto número de casos desta doença em nossa região.

As doenças nutricionais totalizaram 1,6\% dos 1.247 gatos necropsiados no LPV. A inanição foi a causa mais frequente de morte ou eutanásia de gatos nesta categoria, sendo vista principalmente em filhotes $(88,9 \%$ dos casos). Resultados semelhantes foram obtidos em estudo realizado apenas com filhotes felinos, em que distúrbios nutricionais totalizaram 1,8\% dos casos (Cave et al. 2002). Acreditamos que a causa desta taxa de inanição nesta faixa etária se deva principalmente a negligência materna, mesmo motivo apresentado por Cave et al. (2002).

A eutanásia por conveniência foi realizada em 1,4\% dos casos, categoria esta só citada em um trabalho realizado no estado do Paraná, no qual 0,15\% dos gatos foram submetidos à eutanásia por este motivo (Trapp et al. 2010). Os tumores benignos, como hiperplasia fibroepitelial mamária, são os principais motivos para a realização da eutanásia. Acreditamos que o descaso de alguns tutores agregado ao custo financeiro com os tratamentos, seja um dos principais motivos para essa escolha.

Das 1.247 necropsias de gatos avaliados neste estudo a categoria com diagnósticos menos prevalentes foram os distúrbios congênitos com 1\%, semelhante aos 1,7\% encontrado Landes et al. (1984). Esta categoria afeta predominante filhotes $(76,9 \%)$, sendo a hipoplasia cerebelar $(0,2 \%)$ a principal doença diagnosticada nesta categoria. Segundo alguns autores essa alteração pode estar diretamente relacionada à infecção intrauterina pelo parvovírus felino no segundo trimestre de gestação (Addie \& Thompson 2006, Greene \& Addie 2006). Devido à baixa prevalência desta afecção no total de gatos necropsiados no LPV, assim como da forma de enterite clássica da panleucopenia felina $(0,6 \%)$, causada pelo mesmo vírus, acreditamos que possa haver pouca circulação deste vírus em nossa região. Entretanto não há estudos regionais que confirmem ou refutem essa hipótese.

\section{CONCLUSÕES}

Com base nos resultados aqui descritos podemos afirmar que, das categorias propostas, os distúrbios causados por agentes físicos são a causa de morte ou razão para eutanásia mais diagnosticada em gatos na Região Central do Rio Grande do Sul.

Doenças infecciosas e parasitárias, tumores, intoxicações e toxi-infecções, doenças degenerativas e distúrbios iatrogênicos também são categorias comuns.

As principais causas de morte ou razões para eutanásia de gatos, independente das categorias, são: traumas, tumores, DTUIF, PIF, distúrbios iatrogênicos, nefrose tóxica aguda e IRC. Dentre estas, o trauma, o DTUIF, os distúrbios iatrogênicos e a nefrose tóxica aguda acometem principalmente gatos adultos, já os tumores e a IRC afetam geralmente gatos idosos.

A PIF é predominantemente encontrada como causa de morte ou razão para eutanásia em filhotes.

\section{REFERÊNCIAS}

Addie D.D. \& Thompson H. 2006. Panleucopenia felina/Infecção por parvovírus felino, p.467-470. In: Chandler E.A., Gaskell C.J. \& Gaskell R.M. (Eds), Clínica e Terapêutica em Felinos. 3aㅗ ed. Roca, São Paulo.

Andrade R.L.F.S., Oliveira D.M., Dantas A.F.M., Souza A.P., Nobrega Neto P.I. \& Riet-Correa F. 2012. Tumores de cães e gatos diagnosticados no semiárido da Paraíba. Pesq. Vet. Bras. 32(10):1037-1040. http://dx.doi.org/10.1590/ S0100-736X2012001000016.

Barber P.J. 2006. Rins, p.231-255. In: Chandler E.A., Gaskell C.J. \& Gaskell R.M. (Eds), Clínica e Terapêutica em Felinos. 3aㅗ ed. Roca, São Paulo. 
Batista E.K.F., Pires L.V., Miranda D.F.H., Albuquerque W.R., Carvalho A.R.M., Silva L.D.S. \& Silva S.M.M.S. 2016. Estudo retrospectivo de diagnósticos post-mortem de cães e gatos necropsiados no Setor de Patologia Animal da Universidade Federal do Piauí, Brasil de 2009 a 2014. Braz. J. Vet. Res. Anim. Sci. 53(1):88-96. http://dx.doi.org/10.11606/issn.1678-4456. v53i1p88-96.

Bentubo H.D.L., Tomaz M.A., Bondan E.F. \& Lallo M.A. 2007. Expectativa de vida e causas de morte em cães na área metropolitana de São Paulo, Brasil. Ciência Rural 37(4):1021-1026. http://dx.doi.org/10.1590/S010384782007000400016.

Bonnett B.N., Egenvall A., Hedhammar A. \& Olson P. 2005. Mortality in over 350,000 insured Swedish dogs from 1995-2000: I. Breed, gender-, ageand cause-specific rates. Acta Vet. Scand. 46(3):105-120. http://dx.doi. org/10.1186/1751-0147-46-105. PMid:16261924.

Brum J.S., Konradt G., Bazzi T., Fighera R.A., Kommers G.D., Irigoyen L.F. \& Barros C.S.L. 2013. Características e frequência das doenças de suínos na Região Central do Rio Grande do Sul. Pesq. Vet. Bras. 33(10):1208-1214. http://dx.doi.org/10.1590/S0100-736X2013001000006.

Callahan Clark J.E., Haddad J.L., Brown D.C., Morgan M.J., Van Winkle T.J. \& Rondeau M.P. 2011. Feline cholangitis: a necropsy study of 44 cats (1986 e 2008). J. Feline Med. Surg. 13(8):570-576. http://dx.doi.org/10.1016/j. jfms.2011.05.002. PMid:21719332.

Cave T.A., Thompson H., Reid S.W.J., Hodgson D.R. \& Addie D.D. 2002. Kitten mortality in the United Kingdom: a retrospective analysis of 274 histopathological examinations (1986 to 2000). Vet. Rec. 151(17):497-501. http://dx.doi.org/10.1136/vr.151.17.497. PMid:12430997.

Corrêa A.L., Oleskovicz N. \& Moraes A.N. 2009. Índice de mortalidade durante procedimentos anestésicos: estudo retrospectivo (1996-2006). Ciência Rural 39(9):2519-2526. http://dx.doi.org/10.1590/S0103-84782009005000211.

Fighera R.A. \& Graça D.L. 2011. Sistema hematopoiético, p.337-422. In: Santos R.L. \& Alessi A.C. (Eds), Patologia Veterinária. Roca, São Paulo.

Fighera R.A., Souza T.M., Silva M.C., Brum J.S., Graça D.L., Kommers G.D., Irigoyen F.L. \& Barros C.S.L. 2008. Causasde morte e razões para eutanásia de cães da Mesorregião do Centro Ocidental Rio-Grandense (1965-2004). Pesq. Vet. Bras. 28(4):223-230. http://dx.doi.org/10.1590/S0100736X2008000400005.

Gaskell C.J. 2006. Trato urinário inferior, p.256-265. In: Chandler E.A., Gaskell C.J. \& Gaskell R.M. (Eds), Clínica e Terapêutica em Felinos. 3aㅗ ed. Roca, São Paulo.

Greene C.E. \& Addie D.D. 2006. Feline parvovirus infections, p.78-88. In: Greene C.E. (Ed.), Infectious Diseases of Dog and Cat. 3rd ed. Elsevier Saunders, Missouri.

Hall J.0. 2006. Lilies, p.806-11. In: Peterson M.E. \& Talcott P.A. (Eds), Small Animal Toxicology. 2nd ed. W.B. Saunders, Philadelphia. http://dx.doi. org/10.1016/B0-72-160639-3/50056-3.

Headley A.S. 2005. Pneumonia induzida por Aelurostrongylus abstrusus em gatos: achados patológicos e epidemiológicos de 38 casos (1987-1996). Semina, Ciênc. Agrárias 26(3):373-380. http://dx.doi.org/10.5433/1679$0359.2005 v 26 n 3 p 373$.

Hoskins J.D. 2008. Geriatria e Gerontologia do Cão e Gato. 2ª ed. Roca, São Paulo, p.32.

Ilha S.R.M., Loretti A.P., Barros C.S.L., Mazzanti A. \& Breitsameter I. 2004. Cirrose biliar em felinos associada à ectasia do ducto cístico e desvios portossistêmicos extra-hepáticos. Ciência Rural 34(4):1147-1153. http:// dx.doi.org/10.1590/S0103-84782004000400028.

Landes C., Kriegleder H. \& Lengfelder K.D. 1984. Todes- und Erkrankungsursachen bei Katzen anhand der Sektionsstatistik 1969-1982. Tierarztl. Prax. 12(3):369-382. PMid:6093284.

Lucena R.B., Giaretta P.R., Tessele B., Fighera R.A., Kommers G.D., Irigoyen L.F. \& Barros C.S.L. 2012. Doenças de chinchilas (Chinchilla lanigera).
Pesq. Vet. Bras. 32(6):529-535. http://dx.doi.org/10.1590/S0100736X2012000600010.

Lucena R.B., Pierezan F., Kommers G.D., Irigoyen L.F., Fighera R.A. \& Barros C.S.L. 2010. Doenças de bovinos no Sul do Brasil: 6.706 casos. Pesq. Vet. Bras. 30(5):428-434. http://dx.doi.org/10.1590/S0100-736X2010000500010.

Manteigas F. 2013. Causas de mortalidade em gatos com mais de nove anos: Estudo retrospetivo de cem casos. Dissertação de Mestrado Integrado em Medicina Veterinária, Faculdade de Medicina Veterinária, Universidade Lusófona de Humanidades e Tecnologias, Lisboa. 86p.

Mooney C.T. 1995. Geriatria, p.69-75. In: Wills J. \& Wolf A. (Eds), Manual de Medicina Felina. Acribia, Zaragosa.

Moore G.E., Burkman K.D., Carter M.N. \& Peterson M.R. 2001. Causes of death or reasons for euthanasia inmilitary working dogs: 927 cases (1993-1996). J. Am. Vet. Med. Assoc. 219(2):209-214. http://dx.doi.org/10.2460/ javma.2001.219.209. PMid:11469577.

Oliveira F.N., Raffi M.B., Souza T.M. \& Barros C.S.L. 2003. Peritonite infecciosa felina: 13 casos. Ciência Rural 33(5):905-911. http://dx.doi.org/10.1590/ S0103-84782003000500018.

Olsen T.F. \& Allen A.L. 2001. Causes of sudden and unexpected death in cats: a 10-year retrospective study. Can. Vet. J. 42(1):61-62. PMid:11195527.

Pierezan F., Rissi D.R., Rech R.R., Fighera R.A., Brum J.S. \& Barros C.S.L. 2009. Achados de necropsia relacionados com a morte de 335 equinos: 1968-2007. Pesq. Vet. Bras. 29(3):275-280. http://dx.doi.org/10.1590/ S0100-736X2009000300015.

Rissi D.R., Pierezan F., Oliveira Filho J.C., Fighera R.A., Irigoyen L.F., Kommers G.D. \& Barros C.S.L. 2010. Doenças de ovinos da região Central do Rio Grande do Sul: 361 casos. Pesq. Vet. Bras. 30(1):21-28. http://dx.doi. org/10.1590/S0100-736X2010000100004.

Rodaski S. \& Piekarz C.H. 2009. Epidemiologia e etiologia do câncer, p.1-21. In: Daleck C.R., De Nardi A.B. \& Rodaski S. (Eds), Oncologia em Cães e Gatos. Roca, São Paulo.

Rosa F.B., Caprioli R.A., Silva T.M., Galiza G.J.N., Barros C.S.L., Irigoyen L.F., Fighera R.A. \& Kommers G.D. 2013. Doenças de caprinos diagnosticadas na região Central no Rio Grande do Sul: 114 casos. Pesq. Vet. Bras. 33(2):199204. http://dx.doi.org/10.1590/S0100-736X2013000200011.

Souza M.T., Fighera R.A., Langohr I.M. \& Barros C.S.L. 2002. Hiperplasia fibroepitelial mamária em felinos: cinco casos. Ciência Rural 32(5):891894. http://dx.doi.org/10.1590/S0103-84782002000500024.

Stonehewer J. 2006. Fígado e pâncreas, p.358-371. In: Chandler E.A., Gaskell C.J. \& Gaskell R.M. (Eds), Clínica e Terapêutica em Felinos. 3aㅡ ed. Roca, São Paulo.

Togni M., Masuda E.K., Kommers G.D., Fighera R.A. \& Irigoyen L.F. 2013. Estudo retrospectivo de 207 casos de tumores mamários em gatas. Pesq. Vet. Bras. 33(3):353-358. http://dx.doi.org/10.1590/S0100-736X2013000300013.

Trapp S.M., Iacuzio A.I., Barca Junior F.A., Kemper B., Silva L.C., Okano W., Tanaka N.M., Grecco F.C.A.R., Cunha Filho L.F.C. \& Sterza F.D.A.M. 2010. Causas de óbito e razões para eutanásia em uma população hospitalar de cães e gatos. Braz. J. Res. Anim. Sci. 47(5):395-402. http://dx.doi. org/10.11606/issn.1678-4456.bjvras.2010.26821.

Watson P.J. \& Bunch S.E. 2009. Distúrbios hepatobiliares e do pâncreas exócrino, p.485-602. In: Nelson R.W. \& Couto C.G. (Eds), Medicina Interna de Pequenos Animais. $4^{a}$ ed. Elsevier, São Paulo.

Willard M.D. 2009. Distúrbio do sistema digestório, p.351-379. In: Nelson R.W. \& Couto C.G. (Eds), Medicina Interna de Pequenos Animais. 4aㅡ ed. Elsevier, São Paulo.

Wouters F., Barros C.S.L., Wouters A.T.B. \& Kommers G.D. 1998. Síndrome urológica felina: 13 casos. Ciência Rural 28(3):497-500. http://dx.doi. org/10.1590/S0103-84781998000300024. 